\title{
Trans-10, cis-12 Conjugated Linoleic Acid Induces Lipid Degradation and Attenuates Fatty Acid Desaturation in Yeast Saccharomyces cerevisiae
}

\author{
Sanna Hokkanen*, Ossi Pastinen and Alexander D Frey \\ Department of Bioproducts and Biosystems, Aalto University, Finland
}

Submission: February 28, 2017; Published: March 21, 2017

*Corresponding author: Sanna Hokkanen, Department of Bioproducts and Biosystems, School of Chemical Engineering, Aalto University, P.O. Box 16100, FI-00076 AALTO, Finland, Tel: +358-9-47001; Fax: +358-9-462 373; Email: sanna.hokkanen@aalto.fi

Abstract

Yeast has been successfully utilized as a model organism to study the antilipogenic mechanism of the trans-10, cis-12 isomer of conjugated linoleic acid (CLA). The isomer lowered triacylglycerol content of yeast if supplemented in the cultivation medium. Also monounsaturated to saturated fatty acid ratio in yeast lipids was reduced in the CLA treated cells. In this study, the metabolic conditions in terms of lipid reduction were examined to clarify the antilipogenic mechanism of CLA in yeast. Triacylglycerol accumulation and degradation were examined and desaturation of trans-vaccenic acid to cis-9, trans-11 CLA was measured in the trans-10, cis-12 CLA treated cells. The study confirmed that triacylglycerol accumulation was not prevented in the trans-10, cis-12 CLA treated cells evidenced by the intensive co-accumulation of oleic acid. In the trans-10, cis-12CLA treated culture the triacylglycerol content started to decrease and cellular biomass increase in the stationary phase after the cells had shifted their metabolism from fermentation to respiratory metabolism. This indicated that yeast used the liberated fatty acids for $\beta$-oxidation. The lowered capacity to desaturate the trans-vaccenic acid to cis-9, trans-11 CLA pointed out that also desaturase inhibition hasan important role in the antilipogenic mechanism of the trans-10, cis-12 CLA in yeast.

Keywords: Conjugated linoleic acid; Antilipogenic, Fatty acid desaturation; Fatty acid oxidation; Triacylglycerol hydrolysis; Yeast

Abbreviations: CLA: Conjugated Linoleic Acid; FA: Fatty Acid; MUFA: Monounsaturated FA; Ole1p: $\Delta 9$ desaturase; PPAR: Peroxisome Proliferator Activated Receptor; SFA: Saturated FA; TAG: Triacylglycerol; Tgl: Triacylglycerol Lipase

\section{Introduction}

Conjugated linoleic acids (CLA) are a group of linoleic acid isomers having double bonds in conjugated position, i. e. the double bonds are separated by one single bond. Two of the isomers: cis- 9 , trans- $11(c 9, t 11)$ and trans- 10 , cis-12 $(t 10$, c12) CLA, have been shown to have biologically interesting properties. The $c 9, t 11$ CLA has been reported to have anticancer, antidiabetic and anti-inflammatory properties whereas the $t 10$, c12 CLA is known for its antilipogenic ability [1-3].

However, the exact mechanism of the lipid reducing action of $t 10, c 12$ CLA is unclear despite the intensive research with mammalian cells. Evidence for both inhibition of lipid accumulation [4-6] and increased lipid degradation [7-9] caused by $t 10, c 12$ CLA have been found. Clarification of the mechanism would be important in terms of recognizing potential detrimental effects of CLA. On the other hand, the knowledge of the connection between structure and action of CLA could be exploited when new antilipogenic substances are being developed.

Yeast Saccharomyces cerevisiae is a commonly used model organism in eukaryotic lipid metabolism studies. Lipid metabolic pathways share certain homology to higher eukaryotes and yeast might serve as an excellent tool to clarify the function of the $t 10, c 12$ CLA in the eukaryotic cell. If yeast $S$. cerevisiae was cultivated in the medium containing $t 10, c 12 \mathrm{CLA}$, accumulation of triacylglycerols (TAG) was remarkably lower compared to control cultivations [10-12]. If yeast lipase activity was reduced by deleting the two major triacylglycerol lipases, Tgl3p and Tgl4p, TAG accumulated comparably to control irrespective of the presence of $t 10, c 12$ CLA, which indicated that TAG degradation was the reason for the lower TAG amount in the CLA treated wild type yeast [12]. 
One of the evidenced responses of mammals to $t 10, c 12$ CLA administration is increased fatty acid (FA) oxidation. Higher release of $\mathrm{CO}_{2}$ from $\mathrm{C}_{14}$-labeled oleic acid in preadipocytes in the presence of $t 10, c 12$ CLA compared with the control cells reflecting increased FA oxidation was reported [8]. Studies of Zhai et al. [13] showed that both CLA isomers increased mRNA and protein levels of PPAR $\alpha$, a transcription factor controlling the genes of $\beta$-oxidation, but with $t 10, c 12$ isomer the increment was multiple times higher, resulting in enhanced $\beta$-oxidation in 3T3L1 preadipocytes. It was suggested that augmented FA oxidation by $t 10, c 12$ CLA resulted in lower glucose uptake, which prevented the proper storage of the isomer in TAG, and the adipocytes were converted to cells that oxidize FA instead of storing them [9]. This assumption was based on the fact that disruption of FA oxidation restored lipid storage and glucose consumption. The authors also suggested that membrane incorporated $t 10, c 12$ CLA might alter eg. the mitochondrial function due to specific stereochemistry of the isomer. In $S$. cerevisiae, FA oxidation occurs in peroxisomes instead of mitochondria and $\beta$-oxidation is repressed in the glucose containing medium [14]. After glucose exhaustion, glycolytic metabolism is switched to gluconeogenesis and respiratory metabolism, which launches the usage of alternative carbon sources including FA oxidation [15]. The exogenously supplemented or internally released FA induce the expression of the enzymatic machinery for $\beta$-oxidation [16,17]. The expression of the enzymes for $\beta$-oxidation is controlled through the heterodimeric transcription factor Oaf1-Pip2, which binds to a specific sequence, the oleate response element (ORE) in its target genes [18]. Phosphorylation of Oaf1p (and possibly also Pip2p) is needed to activate the heterodimer in non-repressive conditions [19]. After recognition of the FA signal, the Oaf1-Pip2 undergoes a conformational change, which induces transcription of the peroxisomal genes.

Inhibition of FA desaturation is another suggested antilipogenic mechanism of $t 10, c 12$ CLA in mammals. Inhibition of transcription [20,21] and activity [22,23] of the stearoyl-CoA desaturase enzyme (SCD1) by $t 10, c 12$ CLA have been reported. Loss of SCD1 functionality is believed to result in the lowered fat storage in mammals $[24,25]$. In yeast the single $\Delta 9 \mathrm{FA}$ desaturase, Ole1p, is responsible for the monounsaturated FA (MUFA) synthesis $[26,27]$. The enzyme is strictly controlled by external conditions and nutritional status of the yeast cell to preserve FA homeostasis in membrane lipids [28-30]. The impact of $c 9, t 11$ and $t 10, c 12$ CLA isomers on transcript abundance of OLE1 was studied by Hokkanen et al. [12] and different effects between the isomers were found: the $c 9, t 11$ isomer reduced the transcript abundance of OLE1 whereas the t10, c12 CLA had no effect on its transcription. However, the MUFA content was significantly lower in the $t 10, c 12$ CLA treated cell cultures, and the authors suggested that post-transcriptional inhibition of the enzyme occurred in the presence of trans-10 double bond.

The purpose of this research was to find out the conditions which induce TAG degradation by CLA in yeast and whether the enhanced FA oxidation played a role in the lipid reduction. The $t 10, c 12$ CLA has been shown to be degraded efficiently by yeast $\beta$-oxidation [31]. In addition we studied, if the $t 10, c 12$ CLA isomer could induce TAG degradation in the cells, which had accumulated high TAG content before CLA supplementation. Effect of the $t 10, c 12$ isomer on yeast desaturase activity was evaluated by measuring the $c 9, t 11$ CLA formation from transvaccenic acid. The results showed that the CLA isomers induced lipid degradation after the cells had changed their metabolism from fermentation to respiratory mode. The impact was similar irrespective of the timing of the CLA supplementation. Desaturation of endogenous and exogenously supplemented fatty acids was lowered in the presence of the $t 10, c 12$ CLA. Thus, increased lipid degradation and reduced FA desaturation were suggested to be the major lipid reducing effects of the $t 10, c 12$ CLA in yeast $S$. cerevisiae.

\section{Materials and Methods}

\section{Yeast strain and cultivation conditions}

All FA $(t 10, c 12$ CLA; $c 9, t 11$ CLA; oleic acid and transvaccenic acid, $>90 \%$ purity) were supplied by Larodan (Sweden). Wild type S. cerevisiae strain BY4742 (MAT $\alpha$; ura3 $\Delta 0$; leu2 $\Delta 0$; his $3 \Delta 1$; lys $2 \Delta 0$ ) and the deletion strain $\Delta$ pip2 (BY4742; MAT $\alpha$; ura $3 \Delta 0$; leu2 $\Delta 0$; his $3 \Delta 1$; lys $2 \Delta 0$; YOR363c::kanMX4) were ordered from Euroscarf. Yeast was precultivated up to OD(600) $\approx 8$ in YPD medium (yeast extract $20 \mathrm{gL}^{-1}$, bacterial peptone $20 \mathrm{gL}$ ${ }^{1}$, glucose $20 \mathrm{gL}^{-1}$ ) at $30^{\circ} \mathrm{C}$ and shaking at $250 \mathrm{rpm}$ and inoculated thereafter to the fresh YPD medium $\operatorname{COD}(600) \approx 0.05)$. FA were supplemented into the media from the stock solutions $\left(100 \mathrm{gL}^{-1}\right.$ in EtOH) to reach a final concentration of $0.3 \mathrm{gL}^{-1}$. If two different FAs were supplemented, the FA concentration also doubled $\left(0.3+0.3 \mathrm{gL}^{-1}\right)$. The control cultivations were supplemented by the same volume of ethanol. Cell samples $(5 \mathrm{~mL})$ for the lipid analysis were lyophilized and cellular dry weights per volume were determined.

\section{Extraction of lipids}

Cells from $5 \mathrm{~mL}$ of culture were resuspended in $0.5 \mathrm{~mL}$ of $\mathrm{dd} \mathrm{H}_{2} \mathrm{O}$. An equal amount of glass beads $(0.5 \mathrm{~mm}$ diameter) was added and the tubes were vortexed for $45 \mathrm{~min}$ at room temperature. Lysates were transferred to the glass tubes and the lipids were extracted from the cell debris in $2 \mathrm{~mL}$ of dichloromethane-methanol (2:1) by shaking vigorously for three hours. Equal volumes $(0.5 \mathrm{~mL})$ of dichloromethane and $0.1 \mathrm{molL}$ ${ }^{1} \mathrm{HCl}$ were added and the tubes were shaken for an additional hour. The samples were centrifuged for $10 \mathrm{~min}$ at $4500 \mathrm{rcf}$. The lower phase (organic) containing the lipids was collected and dried under a nitrogen stream.

\section{TAG separation and analysis}

Thin layer chromatography (TLC) was performed to separate lipid classes as described by Jaakola et al. [10]. The lipid sample was dissolved in $200 \mu \mathrm{L}$ of dichloromethane-methanol (100:1) and supplemented with standard-mixture containing 
triheptadecanoin(Sigma-Aldrich), phosphatidylcholine, dipentadecanoin (Larodan), and heptadecanoic acid (SigmaAldrich). The sample was applied to the silica plate (Kieselgel 60 , Merck). The TLC chamber contained petroleum ether, diethyl ether and acetic acid in proportions of 80:30:1, respectively. After the front edge was reached, the plate was sprayed with rhodamine 6G to stain the lipid containing spots. The triacylglycerols, glycerophospholipids and FFA were scraped off the plate and methylated for GC analysis as described by Suutari \& Laakso [32]. Agilent 7890 gas chromatograph was equipped with FFAP column (Agilent 19091F-105) and flame ionization detector. Settings for the gas flows were: $\mathrm{H}_{2}, 40 \mathrm{~mL}$ $\mathrm{min}^{-1}$; synthetic air, $380 \mathrm{~mL} \mathrm{~min}^{-1}$; He, $16 \mathrm{mLmin}^{-1}$. The split ratio was $15: 1$. The column temperature was raised from 70 to $200{ }^{\circ} \mathrm{C}$ at rate of $25^{\circ} \mathrm{C} \mathrm{min}^{-1}$ and holding time was $25 \mathrm{~min}$.

\section{Determination of glucose and ethanol concentrations}

Glucose and ethanol were analyzed using a Shimadzu HPLC with the refractive index detector RID-10A. The analytical column used was SP0810 Shodex8.0mm IDx300mm with a BioRad deashing guard column. The eluent was deionized water delivered at a flow rate of $0.7 \mathrm{~mL} \mathrm{~min}^{-1}$ and the column oven (CTO 20A) temperature was $60{ }^{\circ} \mathrm{C}$. Glucose and ethanol were identified and quantified using authentic reagents for external standard calibration using a Class-VP program.

\section{Results and Discussion}

\section{Yeast TAG degradation by CLA is induced upon diauxic shift}

Accelerated TAG degradation was suggested to be the most probable antilipogenic mechanism of $t 10, c 12$ CLA in yeast [12]. In this study, we examined further the impact of the CLA isomers on lipid degradation. In particular, we were interested in determining the time point for induction of TAG hydrolysis. Therefore, we grew yeast cells in the presence or absence of CLA and monitored growth, glucose consumption and ethanol concentration in the media in order to investigate under which condition: fermentation or ethanol utilization, the CLA effects emerge. The Figures $1 \mathrm{~A} \& 1 \mathrm{~B}$ show that growth and glucose consumption of the control cells started earlier than that of the CLA treated cells. In accordance with the faster glucose consumption, ethanol concentrations reached maximal levels already after 13 hours and declined slowly towards the end of the cultivation. The cells cultivated in presence of either of the CLA isomers grew slower in the beginning of cultivation and also ethanol production started later. After depletion of glucose, latest after 20 hours of cultivation, ethanol consumption started. Final ethanol levels in all cultures were comparable. The $c 9, t 11$ isomer inhibited growth more than the $t 10, c 12$ isomer. However, after 24 hours of cultivation and thereafter, the biomass accumulation of the CLA-treated cells exceeded the value of the control cells. TAG amount in the control cells increased continuously reaching the highest value, $27 \mathrm{mgg}^{-1}$, after 50 hours of cultivation (Figure
1C). The most noticeable effect of the CLA treatment was the reduced TAG amount in the later stages of cultivation. This occurred soon after the cells had started to consume ethanol, and both isomers had a similar effect. Because of the lower TAG accumulation at the beginning of cultivation caused by the $t 10$, $c 12$ CLA isomer, the net amount of TAG $\left(14 \mathrm{mg} \mathrm{g}^{-1}\right)$ in the $t 10, c 12$ CLA-treated cells was lower than in the control cells at the end of the cultivation. Thus, the metabolic status after the diauxic shift allowed TAG degradation to take place only in the CLA-treated cells. However, neither increased free FA amounts were found nor was the glycerophospholipid content significantly affected by CLA supplementation, indicating utilization of the FA in $\beta$-oxidation.

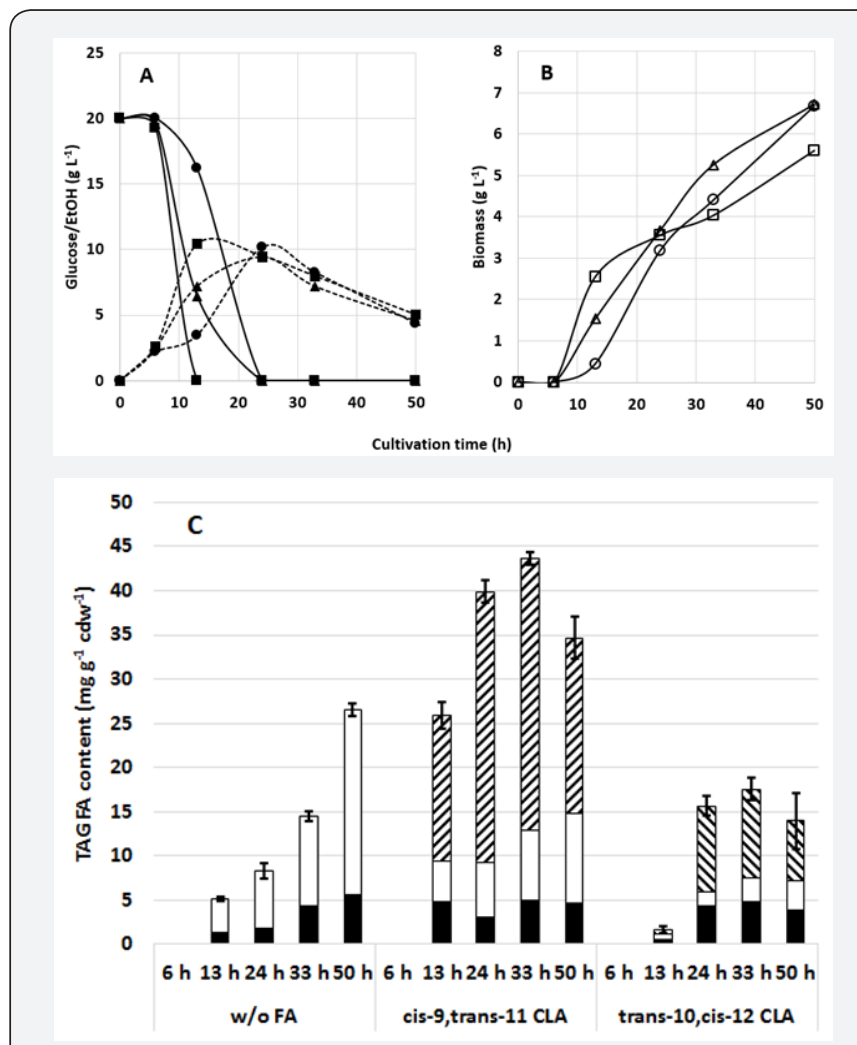

Figure 1: Glucose and ethanol content of the yeast cultures and TAG FA composition of yeast. The $S$. cerevisiae cells were grown with CLA isomers $\left(0.3 \mathrm{gL}^{-1}\right)$ or without FA supplementation (ctrl). Data are averages of two technical replicates of two parallel cultivations. A. Glucose and ethanol content. Filled square, w/o FA supplementation; Filled triangle, cis-9, trans-11 CLA; Filled circle, trans-10, cis-12 CLA. Basic line, glucose content in the medium ( $\left.\mathrm{gL}^{-1}\right)$; Dashed line, ethanol content in the medium $(\mathrm{gL}$ $\left.{ }^{1}\right)$ B. Biomass content. Open square, w/o FA supplementation; Open triangle, cis-9, trans-11 CLA 0.3gL-1; Open circle, trans-10, cis-12 CLA 0.3 $\mathrm{gL}^{-1}$. C. Yeast TAG FA content $\left(\mathrm{mg} \mathrm{g}^{-1} \mathrm{cdw}^{-1}\right)$. Black, saturated FA; White, monounsaturated FA; Slashed right, cis-9, trans-11 CLA, Slashed left, trans-10, cis-12 CLA.

TAG synthesis is not inhibited by $t 10, c 12$ CLA in yeast

TAG accumulation in $t 10, c 12$ CLA fed culture was significantly lower compared to $c 9, t 11$ CLA treated and control culture as shown in Figure 1C and also as previous studies [10-12]. This 
raised a question, whether the TAG formation was attenuated by the $t 10, c 12$ isomer in yeast. Even if the mRNA expression of diacylglycerol acylating enzymes was not inhibited in the $t 10$, c12 CLA-treated culture [12], the inhibition of the enzymatic machinery for TAG formation could not be ruled out in these previous studies. Therefore, we approached the subject by studying, if the $t 10, c 12$ CLA could prevent accumulation of other exogenous FA into TAG. This experiment would show whether the TAG biosynthesis is disturbed by the isomer. Furthermore, it was thus far unclear, whether the $t 10, c 12$ CLA isomer could induce hydrolysis of TAG if supplemented in the later stages of cultivation. Therefore, we conducted a set of experiments to find whether $t 10, c 12$ CLA inhibits lipid accumulation or rather induces degradation of existing lipids.

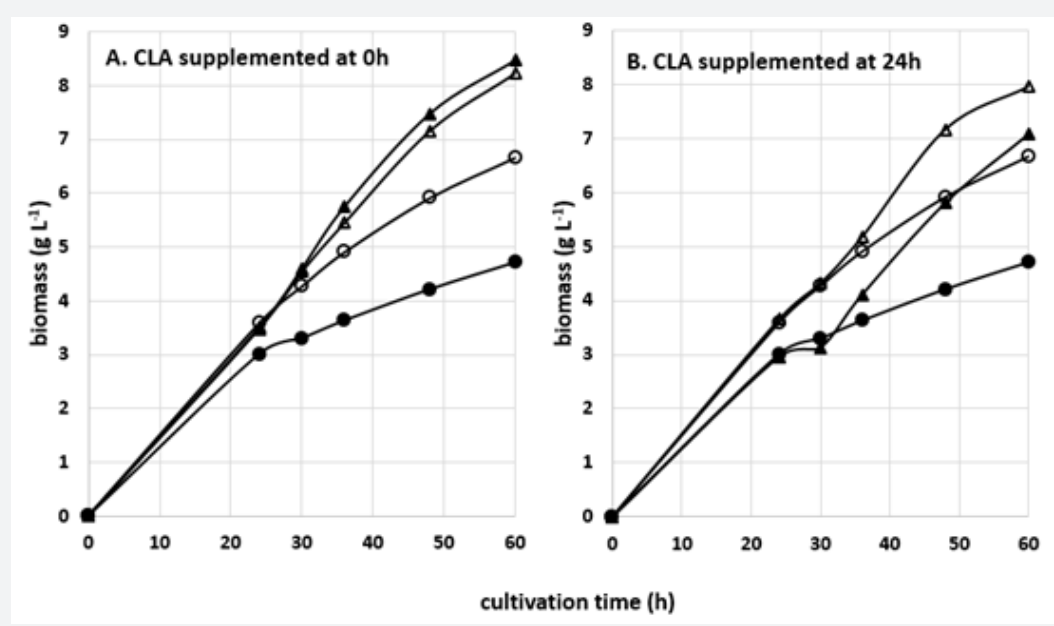

Figure 2: Biomass accumulation in the $S$. cerevisiae cell cultures. The cultures were supplemented with oleic acid $\left(0.3 \mathrm{gL}^{-1}\right)$ in the beginning of the cultivation. A. CLA $\left(0.3 \mathrm{gL}^{-1}\right)$ was co-supplemented in the beginning of the cultivation or B. CLA $\left(0.3 \mathrm{gL}^{-1}\right)$ was co-supplemented after 24 hours of cultivation. The average deviations for the data points were between $0.2-3.0 \%$. Filled circle, w/o FA supplementation; Open circle, trans-10, cis-12 CLA; Filled triangle, oleic acid; Open triangle, oleic acid + trans-10, cis-12 CLA.
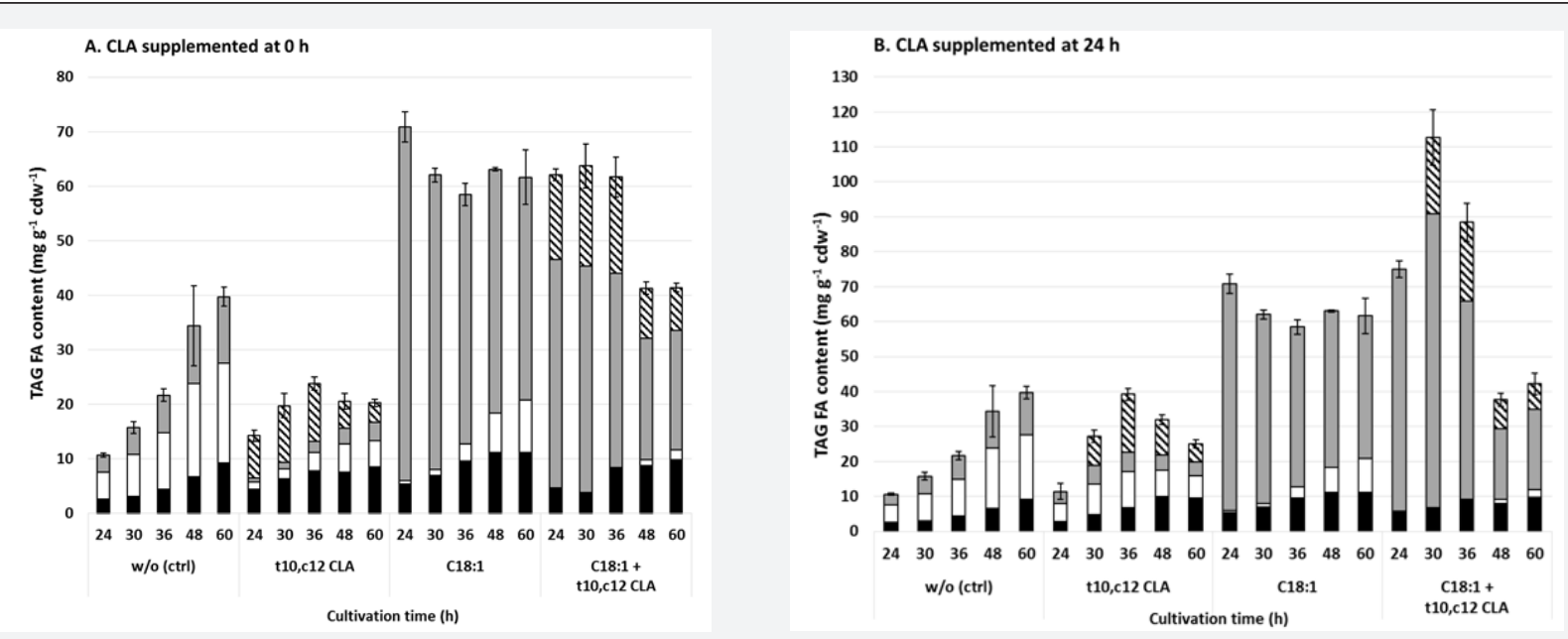

Figure 3: TAG FA content of the yeast cells. S. cerevisiae cultures were supplemented with oleic acid $\left(0.3 \mathrm{gL}^{-1}\right)$ in the beginning of the cultivation. A. CLA $\left(0.3 \mathrm{gL}^{-1}\right)$ was co-supplemented in the beginning of the cultivation or $\mathrm{B}$. CLA $\left(0.3 \mathrm{gL}^{-1}\right)$ was co-supplemented after 24 hours of cultivation. Data are averages of two technical replicates of two parallel cultivations. Black, saturated FA; White, C16:1; Grey, C18:1; Slashed left, trans-10, cis-12 CLA.

The tendency of the isomer to inhibit lipid accumulation was studied first. We cultivated yeast with oleic acid alone or in combination with $t 10, c 12$ CLA to see, if the incorporation of oleic acid was reduced by the CLA isomer. Oleic acid and $t 10$, c12 CLA were added in equal amounts to the cultivation medium and biomass and TAG accumulation were monitored up to 60 hours. Biomass accumulation of the cultures supplemented with FA exceeded the corresponding biomass accumulation of the control cells (Figure 2A). The highest biomass concentration (8.2 g L-1) was obtained in the culture supplemented with the $t 10, c 12$ CLA. Exogenous oleic acid was readily incorporated into TAG which is known to be a way to prevent its lipotoxic effects on membranes [33,34]. In contrast, the $t 10, c 12$ CLA accumulated more moderately (Figure $3 \mathrm{~A}$ ), which could indicate, that TAG synthesis was prevented in the presence of the isomer or the uptake of the isomer was slower compared to oleic acid. As shown 
in Figure 3A, the $t 10, c 12$ CLA lowered the incorporation of oleic acid in TAG fraction. However, the isomer itself incorporated into TAG and total TAG amount was comparable to the levels in the cultivations with oleic acid alone. This proved that TAG accumulation process was not disturbed by the isomer and the enzymes were functioning normally.

The lower accumulation of oleic acid was probably due to the inhibition of yeast endogenous MUFA synthesis in the presence of exogenous unsaturated FA load. Towards the end of the cultivation period, TAG content decreased in the $t 10, c 12$ CLA fed cultures indicating the enhanced lipolysis in the presence of CLA after the diauxic shift. TAG degradation offered building blocks for the membranes of newly forming cells and thus the TAG per cell dry weight was drastically lowered. Because of the low incorporation of the CLA isomer in TAG, there were more CLA compared to oleic acid left in the medium for energy source. This was possibly the reason for the faster cell division after diauxic shift in the CLA supplemented cultures. In the oleic acid supplemented culture the new cells synthesized also C16:1. Instead, in the presence of the $t 10, c 12$ CLA the MUFA synthesis remained low.

The potential of the isomer to induce TAG degradation in yeast cells, which had been made "obese" by oleic acid feeding during cultivation, was studied next. The control and oleic acid $\left(0.3 \mathrm{gL}^{-1}\right)$ supplemented cultures were cultivated for 24 hours before the supplementation with $0.3 \mathrm{gL}^{-1} t 10, c 12$ CLA and we monitored biomass and TAG accumulation. In both cultures, supplementation of $t 10, c 12$ CLA induced higher biomass accumulation soon after the supplementation (Figure $2 \mathrm{~B})$. Figure $3 \mathrm{~B}$ shows how the $t 10, c 12$ CLA first incorporated in TAG and soon thereafter TAG content started to decrease in the CLA-treated cells. Similarly as in Figure 3A, TAG reduction was apparently due to cell growth which utilized FA liberated from TAG of "old cells" as their membrane components. Partly the increased biomass accumulation could be explained by utilization of the CLA directly from the cultivation medium and partly from the hydrolyzed TAG. Both cultures: cells grown with oleic acid or without FA (control cells), responded similarly to the CLA supplementation. Thus, yeast with normal or high TAG content could be induced to lose lipids by $t 10, c 12$ CLA if the isomer was supplemented at later stages of the cultivation.

\section{TAG reduction by $t 10, c 12$ CLA is dependent on yeast FA oxidation capability}

To verify that $\beta$-oxidation and TAG reduction by the $t 10, c 12$ CLA in yeast were connected, we cultivated the wild type and Apip2-strains in the presence of the CLA isomers and measured the TAG content of the cells. Figure 4A shows that in the wild type yeast strain TAG amount was lowered due to the $t 10, c 12$ CLA treatment after 50 hours of cultivation. Instead, the $\Delta$ pip2-strain lacking capacity for $\beta$-oxidation accumulated TAG comparable to the levels observed in control cells despite the presence of $t 10, c 12$ CLA. This indicated that in the presence of $t 10, c 12$
CLA TAG reduction was dependent on $\beta$-oxidation capacity. Higher biomass accumulation gave support for the enhanced $\beta$-oxidation in the $t 10, c 12$ CLA fed culture. Interestingly, a higher biomass accumulation was observed also in the deletion strain. However, supplemented CLA served also as a building block for membranes, which saved other carbon resources for growth. Figure $4 \mathrm{~B}$ shows that $t 10, c 12 \mathrm{CLA}$ was enriched in phospholipids of $\Delta$ pip2 strain supporting this theory. The $c 9$, $t 11$ isomer inhibited strongly the growth of the $\Delta p i p 2$-strain the lag-phase being over 24 hours (data not shown). Therefore, the lipids of the $c 9, t 11$ treated culture couldn't be measured.

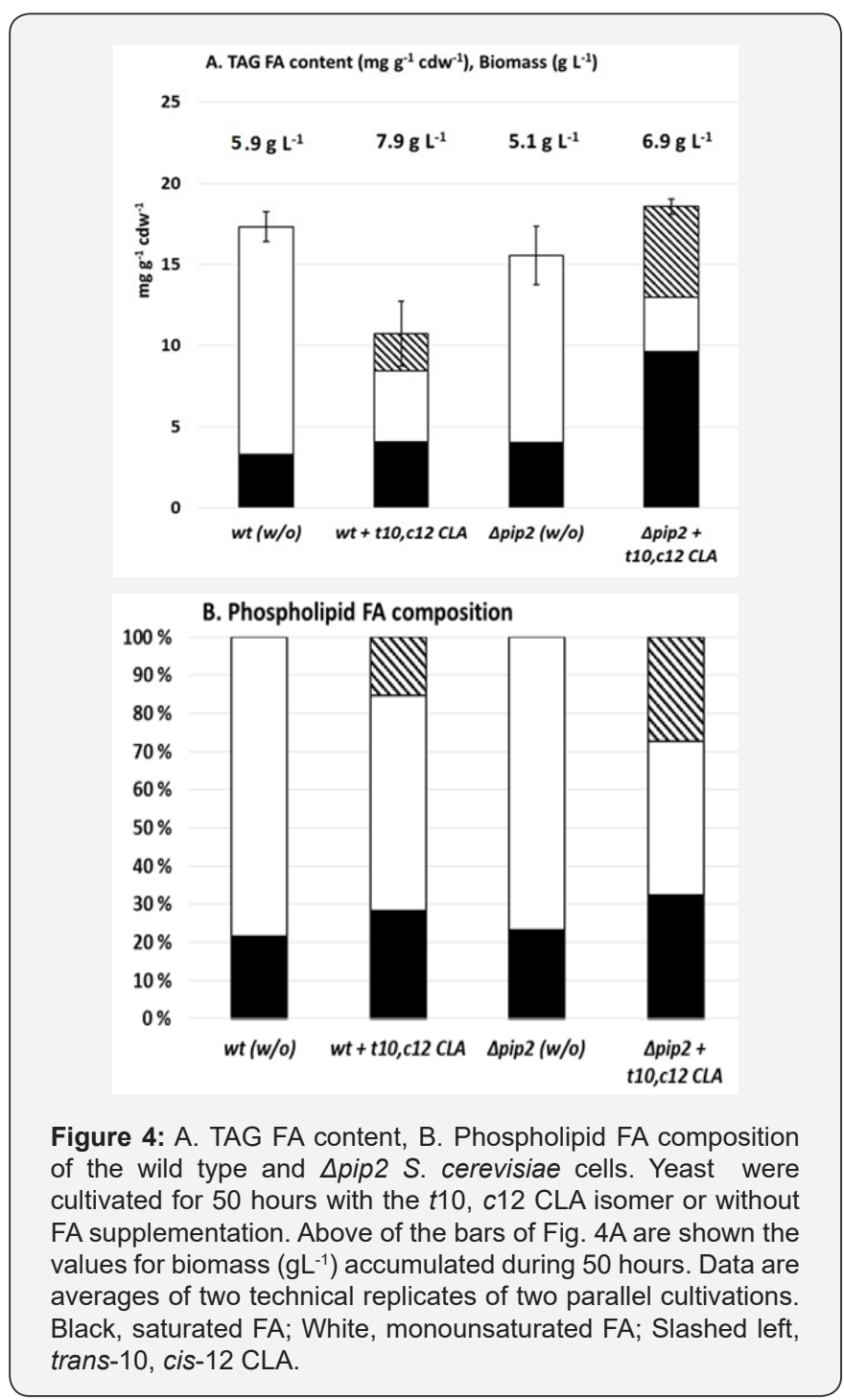

$\Delta 9$ desaturation is attenuated by $t 10, c 12$ CLA in yeast

Previous studies of Hokkanen et al. [12] showed that transcript abundance of OLE1 was not reduced by $t 10, c 12$ CLA despite the fact that MUFA amounts were lowered in the $t 10, c 12$ CLA-treated cells $[10,11]$ and (Figure $1 \mathrm{C}, 3$ \& 4). The desaturase indexes: C16:1/C16:0 and C18:1/C18:0, which were calculated for TAG in the experiment, where the cells cultivated with the CLA isomers for 48 hours (Figure 1C) indicated severely inhibited 
MUFA synthesis (Table 1). Trans-vaccenic acid is known to be converted to $c 9, t 11$ CLA by yeast $\Delta 9$ desaturase Ole1p [35]. Therefore, we compared the formation of $c 9, t 11$ CLA from transvaccenic acid in the wild type cells and $t 10, c 12$ CLA-treated cells to evaluate the effect of the $t 10, c 12$ CLA isomer on desaturase activity. As shown in the Figure 5, the cells cultivated with transvaccenic acid produced $20 \mathrm{mg} \mathrm{g}^{-1} c 9, t 11$ CLA isomer during 48 hours. Instead, if the $t 10, c 12$ CLA was co-supplemented with trans-vaccenic acid, the $c 9$, t11 CLA production was lowered and the cells contained $9 \mathrm{mg} \mathrm{g}^{-1} c 9, t 11$ CLA. Overall incorporation of trans-vaccenic acid was lower in the $t 10, c 12$ CLA-treated cells. This might be due to the reduced capability to convert the potentially detrimental trans-FA to the more favored $c 9, t 11$ CLA. Because also endogenous MUFA production was significantly lowered, the inhibition of desaturase activity could be concluded to be another mechanism besides induction of lipid degradation by which the $t 10, c 12$ CLA reduces lipid content in yeast.
Table 1: Desaturase indexes for $\mathrm{C} 16$ and $\mathrm{C} 18$ fatty acids in yeast triacylglycerols. The yeast cultures were treated with cis-9, trans-11 or trans-10, cis-12 CLA $\left(0.3 \mathrm{~g} \mathrm{~L}^{-1}\right)$ or cultivated without fatty acid supplementation (control).

\begin{tabular}{|c|c|c|c|c|c|c|}
\hline \multirow{2}{*}{$\begin{array}{c}\begin{array}{c}\text { Desaturase } \\
\text { Index }\end{array} \\
\begin{array}{c}\text { Fatty acid } \\
\text { supplemented }\end{array}\end{array}$} & \multicolumn{3}{|c|}{ C16:1/C16:0 } & \multicolumn{3}{|c|}{ C18:1/C18:0 } \\
\hline & $\begin{array}{c}w / o \\
\text { (ctrl) }\end{array}$ & $\begin{array}{c}c 9, t 11 \\
\text { CLA }\end{array}$ & $\begin{array}{l}t 10 \\
c 12 \\
\text { CLA }\end{array}$ & $\begin{array}{c}w / o \\
\text { (ctrl) }\end{array}$ & $\begin{array}{l}c 9 \\
t 11 \\
\text { CLA }\end{array}$ & $\begin{array}{l}t 10, \\
c 12 \\
\text { CLA }\end{array}$ \\
\hline $13 \mathrm{~h}$ & $\begin{array}{c}2.17 \pm \\
0.00\end{array}$ & $\begin{array}{c}0.64 \pm \\
0.15\end{array}$ & $\begin{array}{c}0.68 \pm \\
0.03\end{array}$ & $\begin{array}{c}6.81 \pm \\
0.17\end{array}$ & $\begin{array}{c}1.52 \pm \\
0.56\end{array}$ & $\begin{array}{c}3.97 \\
\pm \\
1.09\end{array}$ \\
\hline $24 \mathrm{~h}$ & $\begin{array}{c}2.61 \pm \\
0.08\end{array}$ & $\begin{array}{c}1.34 \pm \\
0.22\end{array}$ & $\begin{array}{c}0.29 \pm \\
0.00\end{array}$ & $\begin{array}{c}6.85 \pm \\
1.73\end{array}$ & $\begin{array}{c}4.22 \pm \\
0.31\end{array}$ & $\begin{array}{c}0.85 \pm \\
0.02\end{array}$ \\
\hline $33 \mathrm{~h}$ & $\begin{array}{c}1.81 \pm \\
0.10\end{array}$ & $\begin{array}{c}1.17 \pm \\
0.09\end{array}$ & $\begin{array}{c}0.42 \pm \\
0.05\end{array}$ & $\begin{array}{c}4.46 \pm \\
0.01\end{array}$ & $\begin{array}{c}2.89 \pm \\
0.07\end{array}$ & $\begin{array}{c}1.03 \pm \\
0.05\end{array}$ \\
\hline $50 \mathrm{~h}$ & $\begin{array}{c}3.04 \pm \\
0.32\end{array}$ & $\begin{array}{c}1.73 \pm \\
0.01\end{array}$ & $\begin{array}{c}0.70 \pm \\
0.03\end{array}$ & $\begin{array}{c}6.85 \pm \\
0.52\end{array}$ & $\begin{array}{c}3.34 \pm \\
0.01\end{array}$ & $\begin{array}{c}1.63 \pm \\
0.37\end{array}$ \\
\hline
\end{tabular}

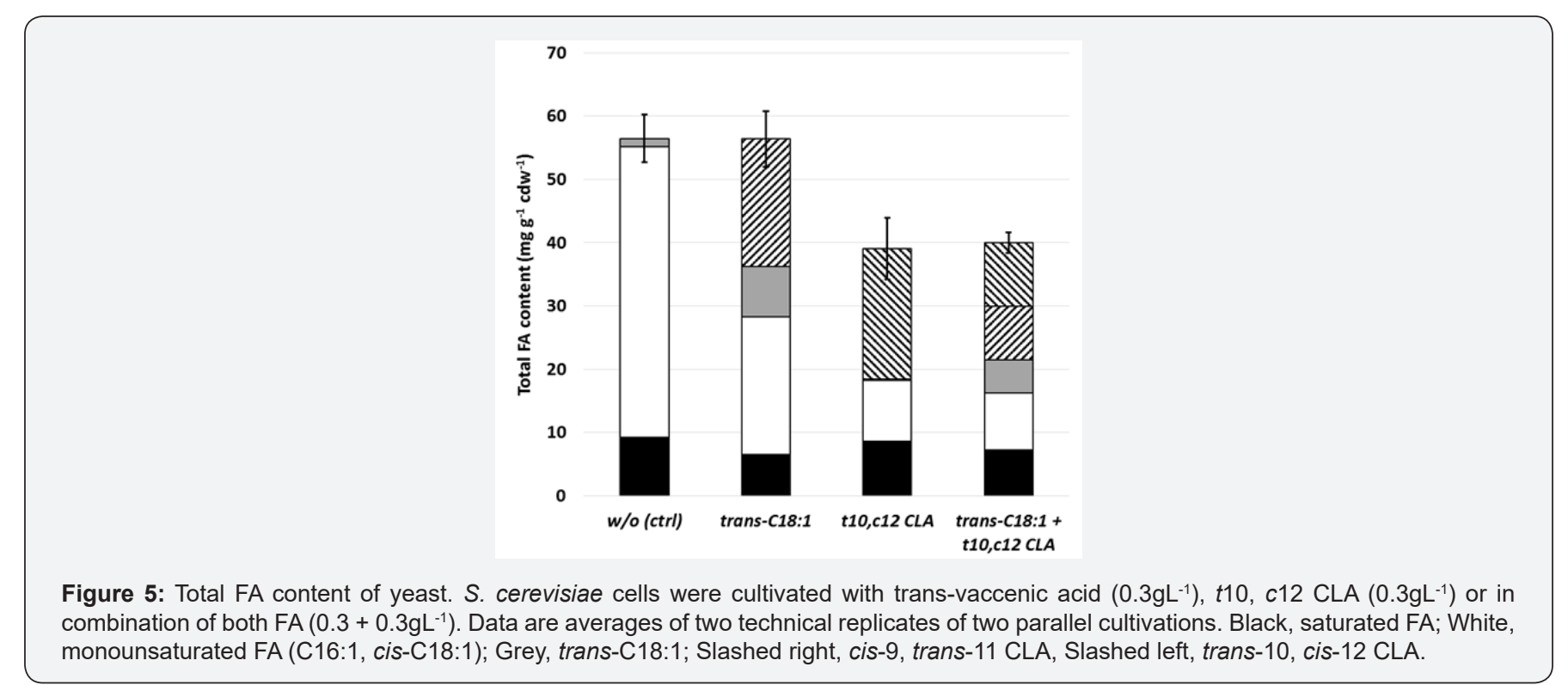

\section{Conclusion}

In this study, a connection between metabolic shift and CLA induced lipid degradation was found in yeast $S$. cerevisiae. Exogenous CLA isomers were incorporated in yeast TAG after supplementation into the medium, but after glucose exhaustion, TAG amount decreased if CLAs were present. The $t 10, c 12$ CLA could reduce TAG content independent of the timing of FA supplementation. Biomass accumulation after $t 10, c 12$ CLA supplementation indicated that the liberated TAG FA were utilized for energy generation through $\beta$-oxidation and as building blocks of newly formed cells resulting in lowered TAG amount per dry cell mass. When $t 10, c 12$ CLA was supplemented in the culture after glucose exhaustion, it was apparently utilized directly for energy to produce more biomass. Enhanced $\beta$-oxidation by $t 10, c 12$ CLA has been proposed to be one of the antilipogenic mechanisms of $t 10, c 12$ CLA in mammals. Yeast Oaf1-Pip2 and mammalian PPAR $\alpha$ regulate $F A$ oxidation in similar manner and they have been shown to bind to similar ligands $[36,37]$. The results of this study support the theory of the enhanced $\beta$-oxidation by $t 10, c 12$ CLA.

In mammals, the PPAR-homologue PPAR $\gamma$ is the transcription factor regulating lipogenesis. The $t 10, c 12$ CLA (but not $c 9, t 11$ CLA) has been shown to act as an antagonist for PPAR $\gamma$ resulting in lowered lipid accumulation by $t 10, c 12$ CLA $[4,38]$. In yeast the PPAR-type regulation of lipogenesis does not exist and this fact might explain why the TAG accumulation was not inhibited in yeast by CLA. Even though the $t 10, c 12$ CLA reduced oleic acid accumulation in TAG, the TAG formation process was not inhibited and lower oleic acid content was more likely resulting from the inhibition of MUFA synthesis by $t 10, c 12$ CLA. If $t 10, c 12$ CLA was added after the growth phase, the MUFA accumulated comparably to control.

Lower lipid content in the $t 10, c 12$ CLA-treated cells was not explained solely by increased lipid degradation. MUFA synthesis 
was found to be drastically reduced, if the $t 10, c 12$ CLA was present. Keeping in mind that desaturase gene transcription was not lowered by the $t 10, c 12$ CLA [12], the desaturase activity was still shown to be reduced by the isomer evidenced by lowered conversion of trans-vaccenic acid to $c 9, t 11$ CLA in the $t 10, c 12$ CLA-treated cells. Desaturase inhibition has been shown previously to have a remarkable role in the fat reducing mechanism of $t 10, c 12$ CLA also in different mammalian cell types $[23,39,40]$ and was apparently an important antilipogenic mechanism also in yeast.

\section{References}

1. Kennedy A, Martinez K, Schmidt S, Mandrup S, La Point K, et al. (2010) Antiobesity mechanisms of action of conjugated linoleic acid. J Nutr Biochem 21(3): 171-179.

2. Lehnen TE, da Silva MR, Camacho A, Marcadenti A, Lehnen AM (2015) A review on effects of conjugated linoleic acid fatty acid (CLA) upon body composition and energetic metabolism. J Int Soc Sports Nutr 12(36): 1-11.

3. Yang B, Chen H, Stanton C, Ross RP, Zhang H, et al. (2015) Review of the roles of conjugated linoleic acid in health and disease. J Functional Foods 15: 314-325.

4. Brown M, Sandberg-Boysen M, Jensen S, Morrision R, Storkson J, et al. (2003) Isomer-specific regulation of metabolism and PPAR $\gamma$ by conjugated linoleic acid (CLA) in human preadipocytes. J Lipid Res. 44(7): 1287-1300.

5. Granlund L, Pedersen JI, Nebb HI (2005) Impaired lipid accumulation by trans 10 , cis 12 CLA during adipocyte differentiation is dependent on timing and length of treatment. Biochim Biophys Acta 1687(1-3): 11-22.

6. Obsen T, Faergeman, NJ, Chung S, Martinez K, Gobern S, et al. (2012) Trans-10, cis-12 conjugated linoleic acid decreases de novo lipid synthesis in human adipocytes. Nutr Biochem 23(6): 580-590.

7. Park Y, Albright KJ, Liu W, Storkson JM, Cook ME, et al. (1997) Effect of conjugated linoleic acid on body composition in mice. Lipids 32(8): 853-858.

8. Evans M, Lin X, Odle J, McIntosh M (2002) Trans-10, Cis-12 Conjugated Linoleic Acid Increases Fatty Acid Oxidation in 3T3-L1 Preadipocytes. J Nutr 132(3): 450-455.

9. den Hartigh LJ, Han CY, Wang S, Omer M, Chait A (2013) 10E, 12Z-conjugated linoleic acid impairs adipocyte triglyceride storage by enhancing fatty acid oxidation, lipolysis, and mitochondrial reactive oxygen species. J Lipid Res 54(11): 2964-2978.

10. Jaakola S, Vahvaselkä M, Laakso S (2005) Effect of CLA on the cellular lipids of Saccharomyces cerevisiae. J Am Oil Chem Soc 8(10): 745-748.

11. Jaakola S, Vahvaselkä M, Laakso S (2006) Positional distribution of conjugated linoleic acid in triacylglycerol of Saccharomyces cerevisiae. J Agric Food Chem 54(15): 5611-5616.

12. Hokkanen S, Laakso S, Senn CM, Frey AD (2010) The trans-10, cis-12 conjugated linoleic acid increases triacylglycerol hydrolysis in yeast Saccharomyces cerevisiae. J Appl Microbiol. doi: 10.1111/jam.13443.

13. Zhai JJ, Liu ZL, Li JM, Chen JP, Jiang L, et al. (2010) Different mechanisms of cis-9, trans-11- and trans-10, cis-12- conjugated linoleic acid affecting lipid metabolism in 3T3-L1 cells. J Nutr Biochem 21(11): 1099-1105.

14. Gancedo JM (1998) Yeast Carbon Catabolite Repression. Microbiol Mol Biol Rev 62(2): 334-361.
15. Brauer MJ, Saldanha AJ, Dolinski K, Botstein D (2005) Homeostatic Adjustment and Metabolic Remodeling in Glucose-limited Yeast Cultures. Mol Biol Cell 16(5): 2503-2517.

16. Veenhuis M, Mateblowski M, Kunau WH, Harder W (1987) Proliferation of microbodies in Saccharomyces cerevisiae. Yeast 3(2): 77-84.

17. Hiltunen JK, Mursula AM, Rottensteiner H, Wierenga RK, Kastaniotis AJ, et al.(2003) Biochemistry of peroxisomal $\beta$-oxidation in the yeast Saccharomyces cerevisiae. FEMS Microbiol Rev 27(1): 35-64.

18. Einerhand AW, Kos WT, Distel B, Tabak HF (1993) Characterization of a transcriptional control element involved in proliferation of peroxisomes in yeast in response to oleate. Eur J Biochem 214(1): 323331.

19. Karpichev IV, Durand-Heredia JM, Luo Y, Small GM(2008) Binding Charasteristics and Regulatory Mechanisms of the Transcription Factors Controlling Oleate-responsive Genes in Saccharomyces cerevisiae. J. Biol Chem 283(16): 10264-10275.

20. Lee KN, Pariza MW, Ntambi JM (1998) Conjugated linoleic acid decreases hepatic stearoyl-CoA desaturase mRNA expression. Biochem Biophys Res Commun 248(3): 817-821.

21. Choi Y, Kim YC, Han YB, Park Y, Pariza MW, et al. (2000) The trans-10, cis-12 isomer of conjugated linoleic acid downregulates stearoyl-CoA desaturase 1 gene expression in 3T3-L1 adipocytes. J Nutr 130(8): 1920-1924.

22. Bretillon L, Chardigny JM, Gregoire S, Berdeaux O, Sébédio JL (1999) Effects of conjugated linoleic acid isomers on the hepatic microsomal desaturation activities in vitro. Lipids 34(9): 965-969.

23. Park Y, Storkson JM, Ntambi JM, Cook ME, Pariza MW (2000) Inhibition of hepatic stearoyl-CoA desaturase activity by trans-10, cis-12 conjugated linoleic acid and its derivatives. Biochim Biophys Acta 1486(2-3): 285-292.

24. Ntambi JM, Miyazaki M, Stoehr JPH, Kendziorski CM, Yandell BS, et al. (2002) Loss of stearoyl-CoA desaturase-1 function protects mice against adiposity. Proc Natl Acad Sci 99(17): 11482-11486.

25. Popeijus HE, Saris WHM, Mensink RP (2008) Role of stearoyl-CoA desaturases in obesity and the metabolic syndrome. Int J Obes 32(7): 1076-1082.

26. Bloomfield DK, Bloch K (1960) The formation of $\Delta$ 9-unsaturated fatty acids. J Biol Chem 235: 337-345.

27. Stukey JE, McDonough VM, Martin CE(1989) Isolation and characterization of $O L E 1$, a gene affecting fatty acid desaturation from Saccharomyces cerevisiae. J Biol Chem 264(28): 16537-16544.

28. McDonough VM, Stukey JE, Martin CE(1992) Specificity of unsaturated fatty acid-regulated expression of the Saccharomyces cerevisiae OLE1 gene. J Biol Chem 267(9): 5931-5936.

29. Choi J-Y, Stukey J, Hwang S-Y, Martin CE (1996) Regulatory elements that control transcription activation and unsaturated fatty acidmediated repression of the Saccharomyces cerevisiae OLE1 gene. J Biol Chem 271(7): 3581-3589.

30. Nakagawa Y, Sakumoto N, Kaneko Y, Harashima S(2002) Mga2p is a putative sensor for low temperature and oxygen to induce OLE1 transcription in Saccharomyces cerevisiae. Biochem Biophys Res Commun 291(3): 707-713.

31. Gurvitz A, Hamilton B, Ruis H,Hartig A, Hiltunen JK(2001) Degradation of conjugated linoleic acid isomers in the yeast Saccharomyces cerevisiae. Biochim Biophys Acta 1533(2): 81-85.

32. Suutari M, Laakso S (1990) Temperature adaptation in yeasts: the role of fatty acids. J Gen Microbiol 136(8): 1469-1474. 
33. Petschnigg J, Wolinski H, Kolb D, Zellnig G, Kurat CF, et al. (2009) Good fat -essential cellular requirements for triacylglycerol synthesis to maintain membrane homeostasis in yeast. J Biol Chem 284(45) 30981 30993.

34. Garbarino J, Padamsee M, Wilcox L, Oelkers PM, D’Ambrosio D, et al (2009) Sterol and diacylglycerol acyltransferase deficiency triggers fatty acid-mediated cell death. J Biol Chem 284(45): 30994-31005.

35. Ando A, Ogawa J, Sugimoto S, Kishino S, Sakuradani E, et al. (2009) Selective production of cis-9, trans-11 isomer of conjugated linoleic acid from trans-vaccenic acid methyl ester by Delacroixia coronata. J Applied Microbiol 106(5): 1697-1704.

36. Desvergne B, Wahli W (1999) Peroxisome Proliferator-Activated Receptors: Nuclear Control of Metabolism. Endocr Rev 20(5): 649-688.

37. Näär AM, Thakur JK (2009) Nuclear receptor-like transcription factors in fungi. Genes Dev 23(4): 419-432.
38. Granlund L, Juvet LK, Pedersen JI, Nebb HI (2003) Trans10, cis12conjugated linoleic acid prevents triacylglycerol accumulation in adipocytes by acting as a PPARgamma modulator. J Lipid Res 44(8): 1441-1452.

39. Choi Y, Park Y, Pariza MW, Ntambi JM (2001) Regulation of stearoylCoA desaturase activity by the trans-10, cis-12 isomer of conjugated linoleic acid in HepG2 cells. Biochem Biophys Res Commun 284(3): 689-93.

40. Choi Y, Park Y, Storkson JM, Pariza MW, Ntambi JM (2002) Inhibition of stearoyl-CoA desaturase activity by the cis-9, trans-11 isomer and the trans-10, cis-12 isomer of conjugated linoleic acid in MDA-MB-231 and MCF-7 human breast cancer cells. Biochem Biophys Res Commun 294(4): 785-790. 